\title{
Peyroni hastalığının hafif ve orta șiddetli kurvatur tedavisinde plikasyon ve greftleme cerrahisi ile sonuçlarımız
}

\section{Treatment of Peyronie's Disease in mild to moderate penile curvature with plication and grafting surgery}

\author{
Ahmet Tahra', Eyüp Veli Küçük', Abdurrahman İnkaya
}

\section{öz}

AMAÇ: Hafif ve orta şiddetli kurvatur olan $\left(30-75^{\circ}\right)$ Peyronie hastalarında, penil plikasyon ve greft yöntemlerinin karşılaştırılması amaçlandı. GEREÇ VE YÖNTEM: 2010-2016 yılları arasında Peyronie hastalığı $(\mathrm{PH})$ tanısıyla opere edilen tüm hastalar retrospektif olarak incelendi. Kurvatur derecesi $30-75^{\circ}$ olan hastalar plikasyon grubu $(n=19)$ ve greftleme cerrahisi grubu $(n=16)$ olarak değerlendirilerek çalışmaya dahil edildi. Kompleks kurvaturu olan hastalar, kum saati deformitesi olanlar, 'menteşe' etkisi görünümü olan hastalar ve ereksiyon problemi nedeniyle penil protez implantasyonu uygulanan hastalar çalışmaya dahil edilmedi. Hastaların preoperatif ve postoperatif 3. ay, 6. ay ve 12 . ayda penil uzunlukları ölçümü yapıldı ve ereksiyon durumları IIEF-5 sorgulama formu kullanılarak değerlendirildi. Başarı, $15^{\circ}$ veya daha az kurvatur olması ve ek herhangi bir tedavi almadan ilişki kurabilme olarak değerlendirildi.

BULGULAR: Hastaların ortalama yaşı 52,6 $\pm 5,4$ idi. Her iki grup yaş ve komorbidite olarak birbirine benzer idi. Kurvatur derecesi plikasyon grubunda $45,2^{\circ} \pm 12,3^{\circ}$ iken greftleme grubunda $50,6^{\circ} \pm 20,1^{\circ}$ idi. Plikasyon grubunda üç hastada (\%15,7) rekürrent kurvatur gözlenirken hastaların penil boyunda ortalama 2,1 $\pm 0,9 \mathrm{~cm}$ kısalma gözlendi. IEFF-5 formunda 3,4 $\pm 1,3$ artış gözlendi. İnsizyon ve greftleme grubunda, hastaların \%93,7'si operasyondan memnun iken, herhangi bir tedaviye gerek olmadan ilişki kurabilen hasta sayısı 13 idi $(\% 81,2)$. Hastalardan ikisinde $(\% 12,5)$ rekürrent kurvatur mevcut idi. IEFF-5 formunda 3,1 $\pm 1,8$ artış gözlendi. Her iki grup karşılaştırıldığında, rekürrens her iki grupta da benzer idi. Ortalama IIEF-5 skorunda, her iki grupta benzer artış gözlendi $(\mathrm{p}=0,8)$.

SONUÇ: Hafif ve orta şiddetli kurvaturu olan Peyroni hastalarında, uygun hasta seçiminde, plikasyon tedavisi ile insizyon ve greftleme yöntemleri etkin ve güvenilir tedavilerdir.

Anahtar Kelimeler: Peyronie hastalı̆ı̆, cerrahi tedavi, plikasyon, greft cerrahisi

${ }^{1}$ Sağlık Bilimleri Üniversitesi, Ümraniye Eğitim ve Araştırma Hastanesi, Üroloji Kliniği, istanbul

Yazışma Adresi/ Correspondence:

Uzm. Dr., Ahmet Tahra

Adem Yavuz Cad. No: 1, İstanbul / Türkiye

Tel. $\quad+905464660346$

E-mail: ahmettahra@gmail.com

Geliş/Received: $\quad$ 14.03.2017

Kabul/Accepted: $\quad 19.03 .2017$

\section{ABSTRACT}

OBJECTIVE: It was aimed to compare penile plication and graft methods in patients with mild to moderate curvature $\left(30-75^{\circ}\right)$ in Peyronie's disease (PD).

MATERIAL AND METHODS: All patients with PD and operated between 2010-2016 were retrospectively reviewed. Patients with 30 to 75 degrees of curvature were included in the study as a group of plication $(n=19)$ and another group of grafting surgery $(n=16)$. Patients with complex curvatures, hourglass deformities, 'hinge' effect appearance, and patients with penile prosthesis implantation due to erection problems were excluded from study. Penile length measurements were taken preoperatively and postoperatively at 3 months, 6 months, and 12 months, and erectile status was assessed using the IIEF- 5 questionnaire. Success was assessed as being 15 degrees and less curvature, and establishing relationships without any additional treatment.

RESULTS: The mean age of the patients was $52.6 \pm 5.4$. Age and comorbidity were similar in both groups. The mean degree of penile curvature was $45.2 \pm 12.3$ degrees in the plication group and $50.6 \pm$ 20.1 degrees in the graft group. Recurrent curvature was observed in 3 patients (15.7\%) in the plication group, whereas on the average $2.1 \pm 0.9$ $\mathrm{cm}$ shortening was observed in penile length of the patients. The mean increase in the IEFF-5 form was $3.4 \pm 1.3$. In the grafting group, $93.7 \%$ of the patients were satisfied with the operation, while the number of patients with whom they were able to establish a relationship without any treatment was $13(81.2 \%)$. Recurrent curvature was present in 2 $(12.5 \%)$ of the patients. The mean increase in the IEFF-5 form was 3.1 \pm 1.8 . Recurrence was similar in both groups. Mean IIEF-5 score increase was similar in both groups $(\mathrm{p}=0.8)$.

CONCLUSION: In patients with mild to moderate curvature, plication therapy and grafting surgery are effective and safe treatments in appropriately selected patients with Peyronie's disease.

Keywords: Peyronie's disease, surgical treatment, plication, graft surgery

\section{Gíriș}

Peyronie hastalığı $(\mathrm{PH})$, penisin tunika albuginea tabak1sının tutulumu ile karakterize, fibrotik plaklar ile giden bir yumuşak doku hastalığıdır. Hastalığın patofizyolojisi henüz tam olarak açıklanamasa da en uzlaşılan teori; tekrarlayan mikrotravmalar sonrasında oluşan inflamasyon ile fibroblast proliferasyonu ve sonrasında oluşan anormal 
kollajen birikimidir. ${ }^{[1]}$ Oluşan fibröz doku ile ağrı, erektil disfonksiyon ve seksüel aktivitede azalma ve kayba kadar gidebilen sonuçlar doğurmaktadır.

Hastalık iki fazdan oluşmaktadır. Akut fazda ağrı, hassasiyet ve progresif deformite oluşumu görülürken, kronik fazda ağrı geriler ve deformite stabilize hale gelir. Hastalığın stabilize hale geldiği ciddi vakalarda cerrahi tedavi altın standarttır. Cerrahi tedavi başlıca üç ana grupta kategorize edilebilir; eğirlik olan penisin dışbükey bölümünün kısaltıldığı girişimler, eğrilik olan penisin içbükey bölümünün uzatıldığı girişimler ve penil protez implantasyonudur. Cerrahi seçiminde kurvaturun lokalizasyonu, deformite tipi, penil uzunluk ve ereksiyonun varlığına göre karar verilmektedir. Genellikle $60^{\circ}$ 'nin altında tunikal kısalma prosedürleri, $60^{\circ}$ nin üstünde, kompleks vakalarda insizyon ve greftleme yöntemleri tercih edilse de aksini bildiren çalışmalar da mevcuttur. ${ }^{[2]}$

Bu çalışmada, orta ve şiddetli $\left(30-75^{\circ}\right)$ ve kompleks olmayan kurvatur hastalarının cerrahi sonuçlarının değerlendirilmesi amaçlandı.

\section{GEREÇ Ve YÖNTEM}

2010-2016 yılları arasında hastanemizin Üroloji Kliniği'nde $\mathrm{PH}$ tanısıyla opere edilen tüm hastalar retrospektif olarak incelendi. Hastaların komorbiditeleri, hastalığı süresi, ereksiyon sırasında ağrı varlığı, ereksiyon ile ilişkili problemi olup olmadığı kaydedildi. Hastalara preoperatif olarak Kombine İntrakavernöz Enjeksiyon ve Stimülasyon Testi (CIS) uygulandı ve Tümesans Testi ile kurvatur derecesi kaydedildi. Hastaların preoperatif ve postoperatif 3 . ay, 6. ay ve 12. ayda penil uzunlukları ölçümü yapıldı ve ereksiyon durumları IIEF-5 sorgulama formu kullanilarak değerlendirildi.

Opere edilen hastalardan, kompleks kurvaturu, kum saati deformitesi, 'menteşe' etkisi görünümü olanlar ve ereksiyon problemi nedeniyle penil protez implantasyonu uygulananlar çalışmaya dahil edilmedi.
Cerrahi teknikte; plikasyon uygulanan hastalara Essed ve Schroder tarafından tariflenen plikasyon yöntemi uygulandi. Cerrahi sütür materyali olarak 2-0 veya 3-0 polyester (Ethibond) sütür kullanıldı. Greftleme tekniğinde ise nörovasküler demet dikkatli bir şekilde disseke edildikten sonra plak insize edildi ve hazırlanan safen ven 4-0 polidiakson sütür ile defekte sütüre edildi ve artifisyel ereksiyon sonrası gereklilik halinde plikasyon sütürleri uygulandı.

Başarı, $15^{\circ}$ veya daha az kurvatur olması ve ek herhangi bir tedavi almadan ilişki kurabilme olarak değerlendirildi. İstatistiksel değerlendirme ki kare ve $\mathrm{t}$ test kullanılarak yapıldı. Çalışma retrospektif olarak yapıldığı için etik kurul onayı alınmadı.

\section{BULGULAR}

Hastaların ortalama yaşı 52,6 $6 \pm 5,4$ idi. Her iki grup, yaş ve komorbidite olarak birbirine benzer idi. Hastalığın süresi plikasyon grubunda $22,2 \pm 12,1$ ay iken greftleme grubunda $21,4 \pm 10,3$ ay olarak hesaplandı ve her iki grup birbirine benzer idi. Demografik veriler Tablo 1'de özetlenmiştir.

Kurvatur derecesi plikasyon grubunda $45,2^{\circ} \pm 12,3^{\circ}$ iken greftleme grubunda $50,6^{\circ} \pm 20,1^{\circ}$ idi. Plikasyon grubunda, dört hastada ventral, beş hastada sağ tarafta, dört hastada sol tarafta, dört hastada dorsumda ve iki hastada dorsolateralde idi. Plikasyon grubunda üç hastada $(\% 15,7)$ rekürrent kurvatur gözlenirken, hastaların penil boyunda ortalama 2,1 $\pm 0,9 \mathrm{~cm}$ kısalma gözlendi. IEFF-5 formunda $3,4 \pm 1,3$ artış gözlendi. Hastaların biri dışında hepsi operasyondan memnun idi $(\% 94,7)$.

Greftleme grubunda deformite, üç hasta dorsolateral, üç hastada ventrolateral, üç hastada dorsumda, dört hastada sağ tarafta ve üç hastada sol tarafta idi. Tüm hastalarda safen ven kullanıldı. Hastaların 3'ünde eş zamanlı plikasyon sütürü de uygulandı. Hastaların \%93,7'si memnun iken, herhangi bir tedaviye gerek olmadan ilişki kurabilen hasta sayısı 13 idi $(\% 81,2)$. Hastalardan ikisinde $(\% 12,5)$ rekürren kurvatur mevcut idi. IEFF-5 formunda $3,1 \pm 1,8$ artış gözlendi (Tablo 2).

Tablo 1. Preoperatif hasta özellikleri

\begin{tabular}{lccc} 
& $\begin{array}{c}\text { Plikasyon grubu } \\
(n=19)\end{array}$ & $\begin{array}{c}\text { insizyon ve greftleme grubu } \\
(n=16)\end{array}$ & $p$ değeri \\
\hline Ortalama yaş & $51,8 \pm 4,8$ & $53,4 \pm 6$ & 0,09 \\
Hastalığın süresi (ay) & $22,2 \pm 12,1$ & $21,4 \pm 10,3$ & 0,6 \\
Komorbidite oranı (\%) & 26 & 25 & 0,8 \\
Kurvatur derecesi ( $\left.{ }^{\circ}\right)$ & $45,2 \pm 12,3$ & $50,6 \pm 20,1$ & $<0,05$ \\
\hline
\end{tabular}




\begin{tabular}{lccc}
\hline & Plikasyon grubu & insizyon ve greftleme grubu & $p$ değeri \\
\hline Kurvatür rekürrensi (\%) & 15,7 & 12,5 & 0,09 \\
IEFF-5 arţ̧̦ı & $3,4 \pm 1,3$ & $3,1 \pm 1,8$ & 0,8 \\
Operasyon memnuniyeti (\%) & 94,7 & 93,7 & 0,12 \\
\hline
\end{tabular}

Her iki grup karşılaştırıldığında, rekürrens her iki grupta da benzer idi. Ortalama IIEF-5 skorunda, her iki grupta da benzer artış gözlendi $(\mathrm{p}=0,8)$. Rekürrens gözlenen hastaların hepsinde komorbidite mevcut idi.

\section{TARTIȘMA}

Peyronie hastalığı, penisin tunika albuginea tabakasının tutulumu ile karakterize bir bağ doku hastalığıdır. Oluşan fibröz plaklar ile, akut dönemde ağrı, kronik dönemde kurvatur oluşumu ve cinsel aktivite kısıtllılı̆ı ile, yaşam kalitesini bozabilen ve psikolojik problemlere yol açabilen bir hastalıktır. ${ }^{[3]}$ Hakkında çok sayıda araştırmanın bulunduğu medikal tedavi ile henüz istenilen noktaya gelinememiştir. ${ }^{[4]}$ İntralezyonel tedavilerden sadece interferon ve kollajenaz clostridium histolyticum tedavisi ile, plasebo kontrollü çalışmalarda anlamlı olarak kurvaturda azalma gözlendiği belirtilmiştir. ${ }^{[5]}$

Cerrahi tedavi, stabil hale gelen, kalsifiye plağı olan, konservatif tedaviye yanıt alınamayan hastalarda altın standarttır. Tunikal kısaltma prosedürlerinde, nörovasküler demet (NVD) disseksiyonu yapılmadan sinir hasarı oluşması engellenir ve bunlar greftleme kadar cerrahi tecrübe gerektirmeyen prosedürlerdir. Greftleme yötemleri ise kompleks deformiteli hastalarda uygulanabilen, ancak daha çok tecrübe gerektiren ve NVD hasarına yol açabilen, grefte bağlı komplikasyonların görülebildiği cerrahilerdir.

Tunikal kısaltma prosedürlerinden, Nesbit yönteminin tedavi başarı oranları \%79-100 arasında değişmekte olup hasta tatmini \%67-100 arasında değişkenlik göstermektedir. ${ }^{[6]}$ Plikasyon tedavisi, tunikal kısaltma yöntemlerinin en çok kullanılanlarından birisidir. Ancak, genellikle 60'nin altında tercih edilmektedir. Çalışmamıza benzer şekilde, Kadıoğlu ve ark. tarafından yapılan bir çalışmada, ortalama $51^{\circ}$ penil kurvaturu olan hastalar, ortalama 24 ay takip edilmiş ve 15 hastanın 14 ünde penil düzelme gözlenmiştir. ${ }^{[7]}$ Van Der Horst ve ark. tarafından yapılan diğer bir çalı̧̧mada, Essed-Schröder tunikal plikasyon yöntemi ile cerrahi tedavi uygulanan, ortalama $55^{\circ}$ kurvatur olan 50 hastanın değerlendirmesinde, hastaların \%90'ında operasyon sonrası cinsel ilişki kurabilecek düzelme saptanmış iken, \%74'ünde penil kısalma gözlenmiştir. ${ }^{[8]}$ Gholami ve
Lue tarafından yapılan ve yüksek derecede kurvaturu olan hastalarda plikasyon tedavisinin değerlendirildiği başka bir çalışmada, $30-120^{\circ}$ (ortalama $64^{\circ}$ ) arasında kurvaturu olan hastalarda 16 nokta plikasyon tekniği uygulanmış, hastaların 6. ay takibinde $\% 93$ oranında penil düzelme gözlenmiştir. Ortalama 2,6 yıllık takipte, hastaların \%15'inde rekürrens gözlenmiştir. ${ }^{[9]}$ Cantoro ve ark. tarafindan yapılan başka bir çalışmada, plikasyon uygulanan ve büyük çoğunluğu $30^{\circ}$ 'nin üstünde kurvaturu olan hastalarda $\% 91$ başarı elde ediliş olup, $60^{\circ}$ 'nin üstünde kurvatur olanlarda bile 3 cm'den daha az kısalma gözlemlenmiştir. ${ }^{[10]}$ Adibi ve ark. tarafindan yapılan kompleks, $>60^{\circ}$ hastalarda deglove etmeden plikasyon tedavisi uygulamış, sadece $\% 14$ hastada penil kısalma tespit edilmiştir. ${ }^{[2]}$ Tunikal plikasyon tedavisinin uygulandığı diğer bir çalışmada ise, ortalama $49^{\circ}$ kurvaturu olan hastaların postoperatif ortalama altı yıllık takibinde, \%93 hastada $30^{\circ}$ 'nin altında kurvatur gözlenmiştir. ${ }^{[11]}$

Plak insizyonu ve greftleme yöntemlerinde ise, dermis, temporalis fascia, ven, perikardium, dura mater, sentetik materyaller, domuz intestinal mukozası (SurgiSIS) başlıca kullanılan materyallerdendir. ${ }^{[12-19]}$ Ven grefti, bilinen ve en çok kullanılan bu çalışmada da tercih ettiğimiz greft materyalidir. Ven grefti ile \%60-95'ler oranında penil düzelme ve \%88-92 oranında tatmin sağlanabilmektedir. ${ }^{[14,20-23]}$ Kadığlu ve ark. tarafından yapılan çalışmada, ortalama $60^{\circ}$ kurvatura sahip 75 hastada $\% 75,7$ tam düzelme sağlandığı belirtilmiştir. ${ }^{[7]}$ Montorsi ve ark.'nın yaptığı, safen ven kullanılarak bugüne kadar en kötü sonuçların bildirildiği bir özet bildiride, 50 hastaya insizyon ve greftleme uygulanmış, tüm hastalarda penil kısalma tespit edilmiş, hastaların \%41'inde azalmış orgazm fonksiyonu gözlenmiştir. ${ }^{[24]}$ Kalsi ve ark.'nın yaptığı diğer bir çalışmada, ortalama kurvaturu $64,5^{\circ}$ olan 40 hastaya insizyon ve venöz greftleme uygulanmış, hastalar beş yıl boyunca takip edilmiş; hastaların \%93'ünde tatmin, \%86'sında tam düzelme gözlenirken \%15'inde erektil disfonksiyon gözlenmiştir. ${ }^{[25]}$ Hsu ve ark. tarafından yapılan başka bir çalışmada ise, derin dorsal ven ve/veya kavernosal ven greftleme materyali olarak kullanılmış, postoperatif olarak hastaların \%90,6'sında tatmin edici düzelme sağlanırken, çalısmamıza benzer bir şekilde, hastaların preoperatif IIEF skoru $19,7 \pm 2,8$ 'den postoperatif $21,6 \pm 2,2$ 'ye yükseldiği gözlenmiştir. ${ }^{[26]}$ 
Tarafımızca bu çalışmada kullanılan safen ven, en çok kullanılan yöntemlerden biri olsa da, ikincil bir insizyona ihtiyaç duyulması, venin çıkarıldığı alan ile ilgili komplikasyonlar (enfeksiyon, lemfosel oluşumu), özenli bir hazırlama gerekliliği ve penil komplikasyonlar (penil histe azalma, gecikmiş ejakülasyon, hematom) görülmesi nedeniyle, iyi bir cerrahi tecrübeye ihtiyaç duyulan operasyonlardandır. ${ }^{[27]}$ Ancak, bizim çalışmamızda bahsedilen komplikasyonlar gözlenmemiştir. Bunun nedenleri arasında; operasyonların aynı merkezde aynı ekip tarafından uygulanması, çalışmaya alınan hastaların kurvatur derecelerinin diğer çalışmalardan daha düşük olması, ven grefti alınırken kalp damar cerrahisi görüşünün alınması sayılabilir.

\section{SONUÇ}

Kompleks olmayan, hafif ve orta şiddetli kurvaturu olan, medikal tedaviye yanıt alınamayan Peyronie hastalarında cerrahi tedavi altın standarttır. Uygun hasta seçiminde, plikasyon tedavisi ile insizyon ve greftleme yöntemleri etkili tedavilerdir. Cerrahi tecrübeye sahip merkezlerde tedavi ile, daha az komplikasyon ve daha yüksek başarı elde edilmektedir. Plikasyon ve greftleme yöntemlerinin karşılaştırılması için randomize kontrollü çalışmalara ihtiyaç vardır.

\section{KAYNAKLAR}

1. Smith JF, Walsh TJ, Lue TF. Peyronie's disease: a critical appraisal of current diagnosis and treatment. Int J Impot Res 2008;20:44559. doi: 10.1038/ijir.2008.30

2. Adibi M, Hudak SJ, Morey AF. Penile plication without degloving enables effective correction of complex Peyronie's deformities. Urology 2012;79:831-5. doi: 10.1016/j.urology.2011.12.036

3. Rosen R, Catania J, Lue T, Althof S, Henne J, Hellstrom W, et al. Impact of Peyronie's disease on sexual and psychosocial functioning: qualitative findings in patients and controls. J Sex Med 2008;5:1977-84. doi: 10.1111/j.1743-6109.2008.00883.x

4. Bilgutay AN, Pastuszak AW. Peyronie's Disease: A Review of Etiology, Diagnosis, and Management. Curr Sex Health Rep 2015;7:117-31. doi: 10.1007/s1 1930-015-0045-y

5. Jordan GH, Carson CC, Lipshultz LI. Minimally invasive treatment of Peyronie's disease: evidence based progress. BJU Int 2014;114:16-24. doi: 10.1111/bju.12634

6. Kadioglu A, Salabaş E. Surgical treatment of Peyronie's disease. In: Minhas S, John Mulhall J, editors. Male Sexual Dysfunction: A Clinical Guide. USA: Wiley-Blackwell; 2017. p.246-57.

7. Kadioglu A, Sanli O, Akman T, Cakan M, Erol B, Mamadov F. Surgical treatment of Peyronie's disease: a single center experience with 145 patients. Eur Urol 2008;53:432-9. doi: 10.1016/j. eururo.2007.04.045

8. Van Der Horst C, Martínez Portillo FJ, Seif C, Alken P, Juenemann KP. Treatment of penile curvature with Essed-Schröder tunical plication: aspects of quality of life from the patients' perspective. BJU Int 2004;93:105-8.

9. Gholami SS, Lue TF. Correction of penile curvature using the 16-dot plication technique: a review of 132 patients. J Urol 2002;167:2066-9.
10. Cantoro U, Polito M, Catanzariti F, Montesi L, Lacetera V, Muzzonigro G. Penile plication for Peyronie's disease: our results with mean follow-up of 103 months on 89 patients. Int J Impot Res 2014;26:156-9. doi: 10.1038/ijir.2014.6

11. Greenfield JM, Lucas S, Levine LA. Factors affecting the loss of length associated with tunica albuginea plication for correction of penile curvature. J Urol 2006;175:238-41. doi: 10.1016/S00225347(05)00063-7

12. Devine CJ Jr, Horton CE. Surgical treatment of Peyronie's disease with a dermal graft. J Urol 1974;111:44-9.

13. Gelbard MK. Relaxing incisions in the correction of penile deformity due to Peyronie's disease. J Urol 1995;154:1457-60.

14. El-Sakka AI, Rashwan HM, Lue TF. Venous patch graft for Peyronie's disease. Part II. outcome analysis. J Urol 1998;160:2050_ 3.

15. Egydio PH, Lucon AM, Arap S. Treatment of Peyronie's disease by incomplete circumferential incision of the tunica albuginea and plaque with bovine pericardium graft. Urology 2002;59:570-4.

16. Chun JL, McGregor A, Krishnan R, Carson CC. A comparison of dermal and cadaveric pericardial grafts in the modified HortonDevine procedure for Peyronie's disease. J Urol 2001;166:185-8.

17. Usta MF, Bivalacqua TJ, Sanabria J, Koksal IT, Moparty K, Hellstrom WJ. Patient and partner satisfaction and long-term results after surgical treatment for Peyronie's disease. Urology 2003;62:105-9.

18. Sampaio JS, Fonseca J, Passarinho A, Cristino J, Mendes J. Peyronie's disease: surgical correction of 40 patients with relaxing incision and dura mater graft. Eur Urol 2002;41:551-5.

19. Knoll LD. Use of porcine small intestinal submucosal graft in the surgical treatment of Peyronie's disease. Urology 2001;57:753-7.

20. Montorsi F, Salonia A, Maga T, Bua L, Guazzoni G, Barbieri L, et al. Evidence-based assessment of long-term results in plaque incision and vein grafting for Peyronie's disease. J Urol 2000;163:1704-8.

21. Backhaus B, Muller S, Albers P. Corporoplasty for advanced Peyronie's disease using venous and/or dermis patch grafting: new surgical technique and long-term patient satisfaction. J Urol 2003;169:981-4. doi: 10.1097/01.ju.0000052403.11923.51

22. Yurkanin JP, Dean R, Wessells H. Effect of incision and saphenous vein grafting for Peyronie's disease on penile length and sexual satisfaction. J Urol 2001;166:1769-72.

23. Adeniyi AA, Goorney SR, Pryor JP, Ralph DJ. The Lue procedure: an analysis of the outcome in Peyronie's disease. BJU Int 2002;89:404-8.

24. Montorsi F, Salonia A, Briganti A, Dehò F, Zanni G, Da Pozzo L et al. Five year follow-up of plaque incision and vein grafting for Peyronie's disease. Eur Urol Suppl 2004:3;33. [Abstract No: 123]. doi.org/10.1016/S1569-9056(04)90125-X

25. Kalsi J, Minhas S, Christopher N, Ralph D. The results of plaque incision and venous grafting (Lue procedure) to correct the penile deformity of Peyronie's disease. BJU Int 2005;95:1029-33. doi: 10.1111/j.1464-410X.2005.05459.x

26. Hsu GL, Chen HS, Hsieh CH, Chen RM, Wen HS, Liu LJ, et al. Long-term results of autologous venous grafts for penile morphological reconstruction. J Androl 2007:28;186-93.

27. Kadioglu A, Küçükdurmaz F, Sanli O. Current status of the surgical management of Peyronie's disease. Nat Rev Urol 2011;8:95-106. doi: $10.1038 /$ nrurol.2010.233 